\title{
The role of folate receptor alpha $(F R \alpha)$ in the response of malignant pleural mesothelioma to pemetrexed-containing chemotherapy
}

\author{
JE Nutt', , ARA Razak', ${ }^{1,3}$ K O'Toole', F Black², AE Quinn', AH Calvert ${ }^{1,3}$, ER Plummer', and J Lunec' \\ 'Northern Institute for Cancer Research, Newcastle University, Framlington Place, Newcastle upon Tyne NE2 4HH, UK; ' Department of Pathology, Royal \\ Victoria Infirmary, Queen Victoria Road, Newcastle upon Tyne NEI 4LP, UK; ${ }^{3}$ Northern Centre for Cancer Care, Freeman Hospital, Freeman Road, \\ Newcastle upon Tyne NE7 7DN, UK
}

\begin{abstract}
BACKGROUND: The standard treatment of choice for malignant pleural mesothelioma is chemotherapy with pemetrexed and platinum, but the clinical outcome is poor. This study investigates the response to pemetrexed in a panel of eight mesothelioma cell lines and the clinical outcome for patients treated with pemetrexed in relation to folate receptor alpha (FR $\alpha$ ).

METHODS: Cell lines were treated with pemetrexed to determine the concentration that reduced growth to $50 \%$ (GI 50 ). $F R \alpha$ expression was determined by western blotting and that of FR $\alpha$, reduced folate carrier (RFC) and proton-coupled folate transporter (PCFT) by real-time quantitative RT-PCR. Immunohistochemistry for FR $\alpha$ was carried out on 62 paraffin-embedded samples of mesothelioma from patients who were subsequently treated with pemetrexed.

RESULTS: A wide range of $\mathrm{Gl}_{50}$ values was obtained for the cell lines, $\mathrm{H} 2452$ cells being the most sensitive ( $\left.\mathrm{Gl}_{50} 22 \mathrm{nM}\right)$ and RS5 cells having a $\mathrm{Gl}_{50}$ value greater than $10 \mu \mathrm{M}$. No FR $\alpha$ protein was detected in any cell line, and there was no relationship between sensitivity and expression of folate transporters. FR $\alpha$ was detected in 39\% of tumour samples, generally in a small percentage of cells. There was no correlation between the presence of FR $\alpha$ and the outcome of pemetrexed treatment, and no significant difference between histological subtypes.

CONCLUSION: Response to treatment with pemetrexed does not depend on the presence of FR $\alpha$.

British Journal of Cancer (2010) I 02, 553-560. doi:I0.1038/sj.bjc.660550I www.bjcancer.com
\end{abstract}

Published online 5 January 2010

(c) 2010 Cancer Research UK

Keywords: Folate receptor $\alpha$; mesothelioma; pemetrexed; cell lines; immunohistochemistry

Malignant pleural mesothelioma (MPM) is an aggressive tumour of the pleura and usually has a poor prognosis. It is increasing in many countries worldwide as a result of widespread exposure to asbestos in the past and is expected to peak around 2015 in the United Kingdom (Hodgson et al, 2005). The disease affects more men than women in a ratio of $5: 1$ and tends to have a long latency period of 20-40 years after asbestos exposure, affecting people in the fifth to seventh decade of life. Approximately $80 \%$ of MPM is attributed to exposure to asbestos fibres, although some tumours are 'spontaneous' with no evidence of asbestos exposure. The outcome of patients with MPM is generally poor, with a median survival of 6-12 months. Most patients are unsuitable for radical surgery. Radiation therapy has been shown to alleviate pain in the majority of treated patients, but the duration of symptom control is short lived, hence chemotherapy is generally the treatment of choice. Clinical trials have shown a partial response rate of $32 \%$ using a combination of pemetrexed and carboplatin (Hughes et al, 2002). A phase III trial using pemetrexed with cisplatin significantly improved response rates, time to progression, overall

*Correspondence: Dr JE Nutt; E-mail: j.e.nutt@ncl.ac.uk Revised 23 November 2009; accepted 26 November 2009; published online 5 January 2010 survival and quality of life, compared with single agent cisplatin, and suggested that this be used as front-line chemotherapy in MPM patients (Vogelzang et al, 2003). Response rate in this study was $41 \%$, with a median survival benefit of 2.8 months, but relapse rates remain high and long-term survival is poor; therefore, improved patient selection for treatment in this disease is still required.

Pemetrexed is a multitargeted antifolate that inhibits several enzymes important in folate metabolism, the main action being on thymidylate synthetase (TS). Inhibition of TS leads to depleted levels of thymidine, which are crucial to DNA synthesis. Pemetrexed also inhibits, to a lesser degree, glycinamide ribonucleotide formyltransferase (GARFT) (Shih et al, 1997). Once in the cell, pemetrexed undergoes polyglutamation, often resulting in a tri- or penta-glutamate tail being added to the parent drug. This process is facilitated by the enzyme folyl-poly glutamate synthetase (FPGS), for which pemetrexed has a high affinity, and results in cellular drug retention. The affinity of pemetrexed to TS is also increased by at least 60 times in the polyglutamated form, compared with the parent drug (Hanauske et al, 2001).

Folic acid and antifolates enter cells by three mechanisms. The reduced folate carrier (RFC) is a bidirectional anion exchanger that has a high affinity for reduced folate co-factors and antifolates, but a low affinity for folic acid. It has a neutral $\mathrm{pH}$ optimum and is 
ubiquitously expressed (Whetstine et al, 2002). The folate receptor alpha $(\mathrm{FR} \alpha)$ is an energy-dependent high-affinity, low-capacity folate-binding protein that delivers folates and antifolates into cells. The low capacity is due to endocytosis of the receptor that has to return to the cell surface in order to function. Expression is limited to specific tissues and is expressed in a characteristic distribution, for example, on syncytiotrophoblastic cells of the placenta and the proximal convoluted tubule of the kidney (Weitman et al, 1992; Mantovani et al, 1994). However, FR $\alpha$ has been reported to be highly expressed in some malignancies: in $90 \%$ of non-mucinous epithelial ovarian cancers (Toffoli et al, 1997) and in $72 \%$ of malignant mesotheliomas (Bueno et al, 2001). Folate receptor alpha has been believed to be important for the physiological transport of folic acid, but not generally for antifolates (Kamen and Smith, 2004). However, there is evidence to suggest that $\mathrm{FR} \alpha$ may have an important role in folate and antifolate transport under certain circumstances. Studies performed on vulval epithelial cell lines A431 and A431-FBP, a highly expressing FR $\alpha$ transfectant, showed that A431-FBP was approximately three-fold more sensitive to pemetrexed than the isogenic non-FR $\alpha$-expressing cell line when cells were maintained in a physiological level of folate (20 nM leucovorin) and was 14-fold more sensitive when maintained in sub-physiological levels $(1 \mathrm{~nm}$ leucovorin) (Theti and Jackman, 2004). Membrane transport of folates has also been recently reported to occur through a ubiquitously expressed proton-coupled folate transporter (PCFT) (Wang et al, 2003; Zhao et al, 2008), a low-pH transporter with a high affinity for pemetrexed.

The contribution of $\mathrm{FR} \alpha$ to pemetrexed transport is likely to be significant in cells in which $\mathrm{FR} \alpha$ is highly expressed. In these situations, transport of pemetrexed via FR $\alpha$ may enhance delivery of the drug to the tumour and potentially enhance response. Recently, a new monoclonal FR $\alpha$ antibody has been developed that can be used for immunohistochemistry on formalin-fixed paraffinembedded (FFPE) tissues (Smith et al, 2007) and therefore be more widely used on stored and more readily transportable tumour specimens. This study investigates the growth inhibitory effects of pemetrexed in eight human mesothelioma cell lines and their FR $\alpha$ status. It also reports the response to treatment with pemetrexed in mesothelioma patients in relation to $\mathrm{FR} \alpha$ immunohistochemistry of the tumours.

\section{MATERIALS AND METHODS}

\section{Cell culture}

Eight human mesothelioma cell lines were used in this study. Five cell lines were of epithelioid type: NCI-H28 (H28), NCI-H2052 (2052), NCI-H2452 (2452) (ATCC, Manassas, VA, USA), NCI-H226 (H226) (Cancer Research, London, UK) and JL1 (DSMZ, Braunschweig, Germany); MSTO-211H (MSTO) (ATCC) was of biphasic origin; two cell lines, DM3 and RS5 (DSMZ) were of sarcomatoid type. Cells were grown in RPMI 1640 (R8758, Sigma-Aldrich, Poole, $\mathrm{UK})$ containing $2 \mathrm{~mm}$ glutamine, $1.5 \mathrm{gl}^{-1}$ sodium bicarbonate, $4.5 \mathrm{gl}^{-1}$ glucose, $10 \mathrm{~mm}$ HEPES, $1 \mathrm{~mm}$ sodium pyruvate and either $10 \%$ foetal bovine serum (FBS) (Sigma-Aldrich) or $10 \%$ dialysed FBS (DFBS) (Invitrogen, Faisley, UK). Dialysis of serum removes low molecular weight compounds such as thymidine and homocysteine, which may affect the response of cells to pemetrexed. The concentration of folic acid in the medium used is $2 \mu \mathrm{M}$. All cell lines were subcultured regularly and were negative for mycoplasma.

Growth-inhibition studies using pemetrexed were carried out using the SulfurRhodamine B (SRB) (Skehan et al, 1990) assay in 96-well tissue culture plates as previously described (Nutt et al, 2004). Cells were seeded at $5 \times 10^{3}$ cells per well and treated with $10 \mathrm{~nm}$ to $10 \mu \mathrm{m}$ pemetrexed for approximately three cell doubling times, apart from the slower growing RS5 and DM3 cells that were treated for 6 days. The concentration of pemetrexed resulting in
$50 \%$ growth inhibition $\left(\mathrm{GI}_{50}\right)$ for each cell line was calculated using GraphPad Prism software.

Cell lysates required for western blotting were prepared after washing cells with ice-cold PBS and addition of lysis buffer (62.5 mM Tris/ $\mathrm{HCl} \mathrm{pH} 6.8,2 \%$ sodium dodecyl sulphate and $10 \%$ glycerol).

\section{Western blotting}

Western blotting was carried out to determine the presence and level of expression of FR $\alpha$ protein. Cell lysates were prepared and $20 \mu \mathrm{g}$ aliquots of protein (calculated from quantification using the Pierce BCA protein assay) from each sample were loaded on a 4$20 \%$ gradient polyacrylamide gel (Invitrogen). After SDS-PAGE and electroblotting (Towbin et al, 1979), membranes were treated for $1 \mathrm{~h}$ with TBS-Tween buffer containing $5 \%$ milk to block nonspecific binding and then incubated with a previously described and validated monoclonal mouse $\mathrm{FR} \alpha$ primary antibody (Smith et al, 2007) for $1 \mathrm{~h}$ at room temperature. Secondary HRP-conjugated antibody (goat anti-mouse, Dako, Ely, UK) was used to detect the primary antibodies and antibody-labelled protein bands were visualised by enhanced chemiluminescent detection (ECL) (GE Healthcare, Little Chalfont, UK). Equal loading of protein was verified using a mouse anti-tubulin antibody (Sigma-Aldrich). IGROV1 (an ovarian cancer cell line) cell lysate was used as a positive control and Jurkat cell lysate was used as a negative control for FR $\alpha$.

\section{Quantitative RT - PCR}

RNA was extracted from cells using the Qiagen RNAeasy minikit (Qiagen, Hilden, Germany) and reverse transcribed using TaqMan reverse transcriptase reagents (Applied Biosystems, Warrington, UK). A volume of $2.5 \mu \mathrm{l}$ cDNA was used for quantitative real-time PCR in a total volume of $10 \mu \mathrm{l}$, repeated in triplicate, using the TaqMan gene expression assay Hs00357143_g1 for FR $\alpha$, Hs00953344_m1 for RFC, Hs00611082_m1 for PCFT and Hs99999901_s1 for 18S (all from Applied Biosystems), as well as universal mastermix. The expected amplicon sizes were $89,106,72$ and 187, respectively. PCR was performed as follows: $50^{\circ} \mathrm{C}$ for $2 \mathrm{~min}, 95^{\circ} \mathrm{C}$ for $10 \mathrm{~min}$, and 40 cycles of $95^{\circ} \mathrm{C}$ for $15 \mathrm{~s}$ and $60^{\circ} \mathrm{C}$ for $1 \mathrm{~min}$ using the $\mathrm{ABI}$ Prism $7900 \mathrm{HT}$ sequence detection system (Applied Biosystems). Results were quantified relative to $18 \mathrm{~S}$, and calibrated to the IGROV1 FR $\alpha$ estimation.

\section{Immunohistochemistry and clinical correlation}

Eligible patients were identified from chemotherapy prescription records. All patients underwent histological diagnosis of malignant pleural mesothelioma and were treated according to our institutional protocol, in which carboplatin was administered to produce a value of the area under the curve (AUC) of 5, i.v. over $30 \mathrm{~min}$ on day 1 (or cisplatin $75 \mathrm{mg} \mathrm{m}^{-2}$, i.v. administered over $3 \mathrm{~h}$ on day 1 ) and pemetrexed administered at a dose of $500 \mathrm{mg} \mathrm{m}^{-2}$ i.v. for $10 \mathrm{~min}$ on day 1 . Cycles were repeated every 21 days to a maximum of six cycles. Patients also received folic acid supplementation at a dose of $400 \mu \mathrm{g}$ daily, beginning at least 7 days before the first dose of pemetrexed and one injection of $1000 \mu \mathrm{g}$ vitamin B12 intramuscularly 7-14 days before beginning the treatment. Folic acid was continued, and vitamin $B_{12}$ was repeated every 12 weeks, throughout the treatment until 21 days after the last dose of pemetrexed. Dexamethasone, $4 \mathrm{mg}$ twice daily, was given orally on the day before, the day of and the day after therapy. Our antiemetic regimen included a serotonin antagonist. Chemotherapy was discontinued in the event of disease progression, unacceptable toxicity or after completion of six cycles. Cycles were repeated at $100 \%$ of the intended doses if neutrophil and platelet counts were $\geqslant 1.5 \times 10^{9} 1^{-1}$ and $\geqslant 100 \times 10^{9} 1^{-1}$, respectively. If any dose 
reduction occurred, patients continued to receive the reduced dose throughout their treatment. All patients underwent planned radiographic evaluation.

Sections of $4 \mu \mathrm{m}$ were cut from FFPE tissue blocks of identified patients and mounted on SuperFrost Plus microscope slides (VWR International, Lutterworth, UK) and allowed to dry at $56^{\circ} \mathrm{C}$. The slides were dewaxed in xylene, rehydrated in graded ethanol and incubated for $10 \mathrm{~min}$ in $0.5 \%$ hydrogen peroxide solution to block endogenous peroxidase activity. The slides were then treated with an endogenous biotin blocking kit (Dako) before high-temperature antigen retrieval (microwaved thrice for $5 \mathrm{~min}$ in citrate buffer $\mathrm{pH}$ 6.0). Blocking with a 1 in 5 dilution of normal goat serum for $10 \mathrm{~min}$ preceded overnight incubation in a 1 in 20 dilution of $\mathrm{FR} \alpha$ antibody (Smith et al, 2007) at $4^{\circ} \mathrm{C}$. Detection of the primary antibody was carried out using biotinylated goat antimouse secondary antibody and was visualised using DAB. Between each incubation step, slides were rinsed in TBS $\mathrm{pH} 7.6$ for $2 \times 5 \mathrm{~min}$ washes. Negative controls with no primary antibody were used and a FFPE section of renal tissue was used as a positive control.

Staining was graded independently by two assessors (JN and AR) using a composite index. The intensity of staining was scored $0-3$, with 0 being no staining, 1 weak staining, 2 moderate staining and 3 intense staining. This was multiplied by the percentage of tumour area stained, using 10 for upto $10 \%, 25$ for $11-25 \%, 50$ for $26-50 \%, 75$ for $51-75 \%$ and 100 for $76-100 \%$ of the tumour area stained, giving a composite score range of $0-300$. The staining obtained in the renal tissue was used as a reference for intense staining, with a score of 300 .

The composite score for the $\mathrm{FR} \alpha$ immunohistochemistry of tumour samples was correlated to clinical parameters such as response (objective decrease in tumour size on CT imaging), disease control rate (DCR, presence of stable disease or better on $\mathrm{CT}$ ), time-to-treatment failure (TTF, time from treatment initiation to documented clinical or radiological progression) and overall survival (OS, time from treatment initiation to death from any cause).

This study was approved by the local research ethics committee and the Newcastle Hospitals Caldicott Guardian.

\section{RESULTS}

\section{Cell culture}

Pemetrexed inhibited the growth of mesothelioma cell lines to variable extents. Representative graphs showing patterns of growth inhibition for each cell line in medium containing FBS or DFBS are shown in Figure 1. The mean $\mathrm{GI}_{50} \pm$ s.d. value from three replicate experiments is shown in Table $1 . \mathrm{GI}_{50}$ values ranged from $14 \mathrm{~nm}$ in the H2452 epithelioid cell line to greater than $10 \mu \mathrm{m}$ in the sarcomatoid cell line RS5. In most cases, apart from sarcomatoid RS5 cells, those grown in medium containing DFBS were more sensitive to pemetrexed than cells grown in medium containing normal FBS, with the largest difference observed in JL1 and DM3 cell lines. This is probably because of the removal of molecules such as folates, thymidine and homocysteine from the serum on dialysis, which are able to rescue cells from the effects of pemetrexed.

\section{Western blotting and quantitative RT - PCR}

The results for western blotting and quantitative RT-PCR are shown in Figure 2. In western blotting, there was no evidence of any $\operatorname{FR} \alpha$ protein in any of the mesothelioma cell lines, but was shown to be present at high levels in the IGROV1 ovarian cell line positive control. Similarly, the results from real-time PCR showed $\mathrm{FR} \alpha$ mRNA to be undetectable in three cell lines (JL1, DM3 and
RS5), whereas extremely low levels at the limit of detection were present in the other mesothelioma cell lines. In these cell lines, the level of expression for $\mathrm{FR} \alpha$ was approximately 100 times less than the highly expressing IGROV1 ovarian cancer cell line.

The results from real-time RT-PCR for other folate transporters, RFC and PCFT, in the cell lines are shown in Figure 3. The relative expression of both these transporters varied between the cell lines, with the most variation observed in RFC. There was no correlation between RFC and PCFT with the $\mathrm{GI}_{50}$ of pemetrexed in the cell lines.

\section{Immunohistochemistry and clinical correlation}

In all, 62 patients were eligible for this study. A summary of demographics and treatment details is shown in Table 2.

A sample of the positive control and various staining intensities are depicted in Figure 4. FR $\alpha$ expression was considered to be positive when the composite score was $>0$. FR $\alpha$ expression was positive in 24 of the 62 samples examined (39\%, composite score range: $5-142.5$ ). Both membranous and cytoplasmic staining was seen. When present, however, FR $\alpha$ expression was usually weak as $12(50 \%)$ stained samples had a score of 30 or less. Only two samples had a composite score of more than 100. FR $\alpha$ expression was seen to be higher in the epithelioid disease subtype but was not significant (epithelioid, $n=16(44 \%)$, biphasic, $n=6(35 \%)$ and sarcomatoid, $\left.n=2(22 \%), \times^{2} 1.614, P=0.45\right)$.

There were no significant differences in the proportion of patients with a response or disease control when subdivided into those with a positive or negative expression of FR $\alpha$. Responses were seen in $8(33 \%)$ and $9(24 \%)$ patients with positive and negative FR $\alpha$-stained tumours $(P=0.56$, Fisher's exact test), whereas 75 and $61 \%$, respectively, had disease control $(P=0.28$, Fisher's exact test). The TTF and OS rates were not statistically different between patients with positive FR $\alpha$ tumours and those that were negative (median TTF 7.4 vs 5.1 and OS 10.4 vs 8.6 months, $\log$ rank $P=0.61$ and 0.74 , respectively), as shown in Figure 5. The results in terms of treatment response, DCRs, TTF and OS were similar when comparing higher expression (composite score $>30$ ) against low or no expression of FR $\alpha$.

\section{DISCUSSION}

Antifolates have been developed over the years to inhibit a number of folate-dependent enzymes. Methotrexate primarily targets dihydrofolate reductase, raltitrexed targets thymidylate synthase and the more recently introduced pemetrexed has multiple targets in the folate pathway. The role of FR $\alpha$ in the uptake of both folates (essential for cellular purine and pyrimidine biosynthesis and eventually DNA synthesis) and antifolates has been the subject of numerous publications with contrasting results (Chattopadhyay et al, 2004; Theti and Jackman, 2004). Chemotherapy for mesothelioma, using pemetrexed and platinum, is now the standard treatment of choice. In mesothelioma, FR $\alpha$ has been described as highly activated (Bueno et al, 2001), with $72 \%$ of 61 mesotheliomas showing a two- to four-fold higher mRNA expression compared with normal control tissues. Immunohistochemical studies using Mov 18 and Mov 19 antibodies on frozen sections confirmed the results by demonstrating $\mathrm{FR} \alpha$ at the cellular membrane in 13 of 17 samples. However, a later study (Khokhar et al, 2002) demonstrated that despite some expression of $\mathrm{FR} \alpha$ in human mesothelioma cells, internalisation of methotrexate was predominantly carrier mediated. A highly variable expression of both RFC and FR $\alpha$ was found by RT-PCR in a number of mesothelioma samples. With the development of a novel FR $\alpha$ antibody for use in paraffin-embedded tissues, in this paper, the role of $\mathrm{FR} \alpha$ in stored mesothelioma samples has been related to the response of treatment to pemetrexed. The effect of pemetrexed in 

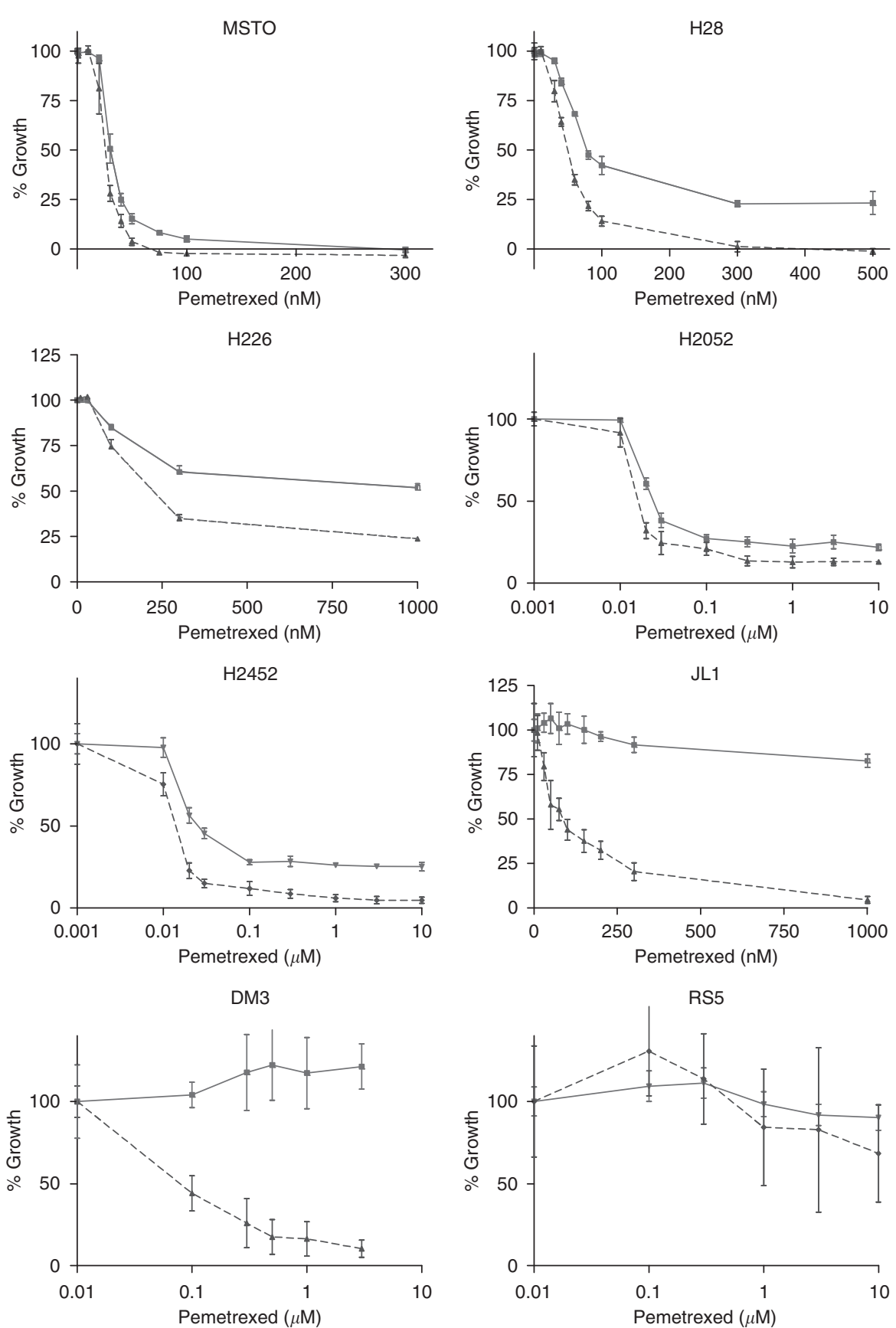

Figure I Effect of pemetrexed on growth of mesothelioma cell lines grown in medium containing foetal bovine serum (FBS) (solid line) or dialysed foetal bovine serum (DFBS) (dashed line) with s.d. $(n=6)$ for one representative experiment.

Table I Mean $\mathrm{Gl}_{50}$ values $(n M) \pm$ s.d. $(n=3)$ for pemetrexed in mesothelioma cell lines grown in medium containing foetal bovine serum (FBS) or dialysed FBS (DFBS)

\begin{tabular}{|c|c|c|c|c|c|c|c|c|}
\hline Cell line & MSTO & $\mathrm{H} 28$ & H226 & D2052 & D2452 & JLI & DM3 & RS5 \\
\hline
\end{tabular}

relation to $\mathrm{FR} \alpha$ in a selection of mesothelioma cell lines has also been established.

The panel of mesothelioma cell lines used included cells of both epithelioid and sarcomatoid types. Generally, tumours of the sarcomatoid type are less responsive to chemotherapy. This was reflected in the sensitivity of cell lines to continuous pemetrexed treatment, which showed that sarcomatoid cell lines (RS5 and DM3) were less sensitive to pemetrexed than the other cell lines. Clinically, sarcomatoid tumours tend to be more aggressive than epithelioid tumours (Herndon et al, 1998). In RPMI medium, 


\section{A}
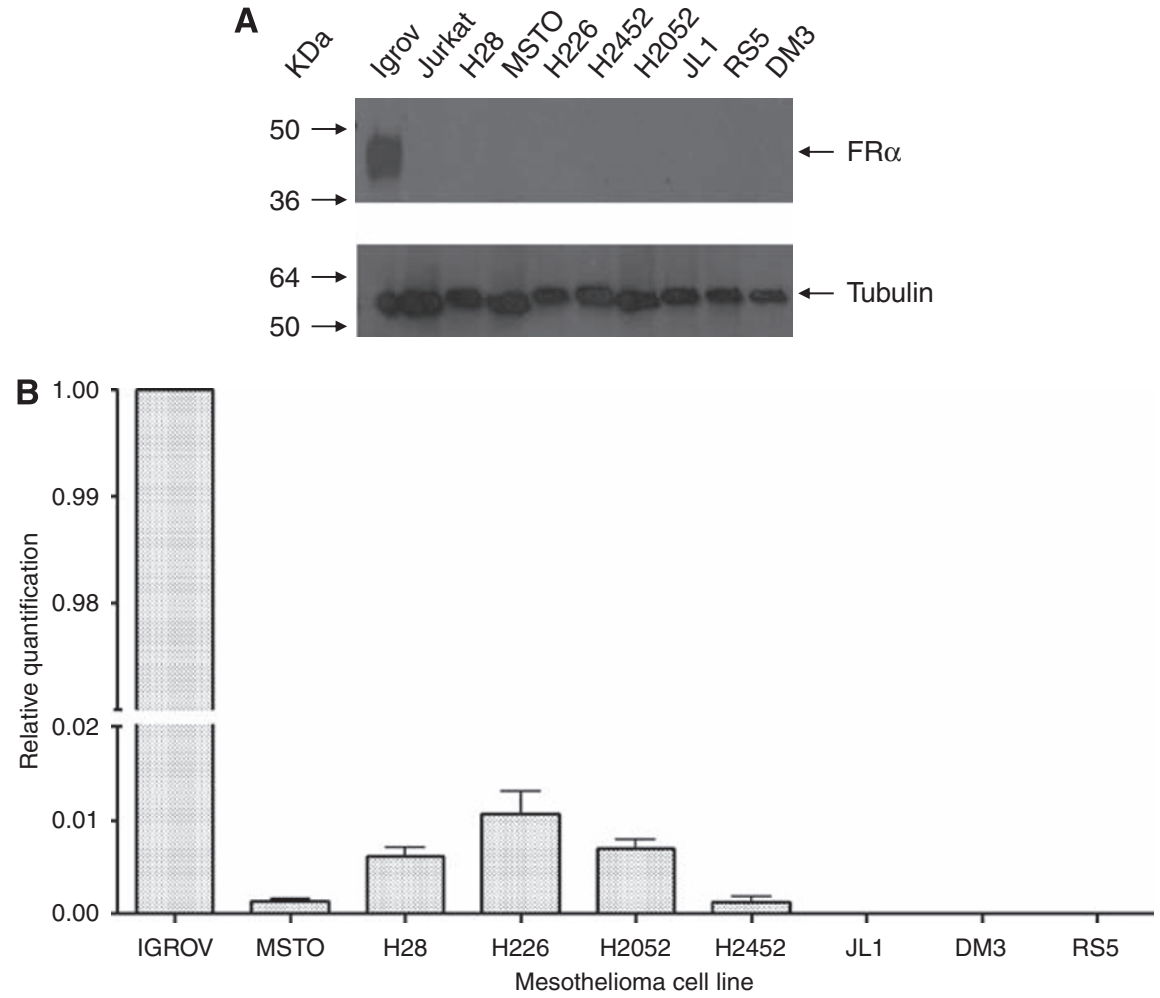

Figure 2 (A) Western blot analysis of folate receptor alpha $(F R \alpha)$ in mesothelioma cell lysates. IGROVI was used as a positive control and Jurkat as a negative control. Tubulin antibody shows equal loading in all lanes. Each antibody showed a single band, as shown in the cropped gels. (B) Quantification of FR $\alpha$ mRNA by real-time PCR in mesothelioma cell lines relative to FR $\alpha$-positive IGROVI cells.

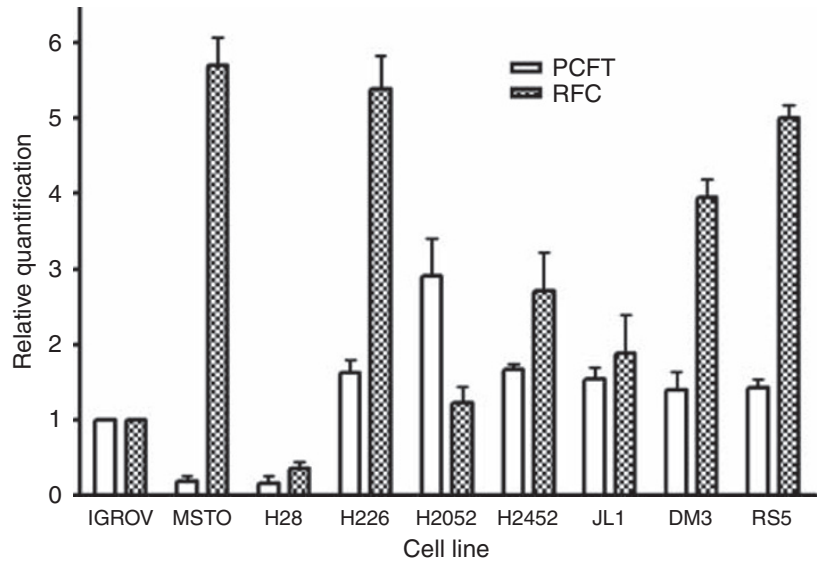

Figure 3 Quantification of reduced folate carrier (RFC) and protoncoupled folate transporter (PCFT) mRNA by real-time PCR in mesothelioma cell lines relative to IGROVI cells. Error bars show s.d., $n=3$.

sarcomatoid cells were also slower growing (with doubling times of 3-4 days) than epithelioid cells (with doubling times of 1-2 days). A recent report on cell proliferation rates in samples of mesothelioma, using the Ki-67 proliferation index (PI), showed that biphasic tumours had a higher PI than epithelioid and sarcomatoid types, and that the median value for epithelioid samples was higher than that of sarcomatoid tumours (Cakir et al, 2006 ), although only $4.5 \%$ of tumours were of the sarcomatoid type.

In all cell lines in which a $\mathrm{GI}_{50}$ value was reached, this value was lower when DFBS, rather than normal FBS, was used in the medium. This will have been due to removal of small molecules such as folates, thymidine and homocysteine from the serum on
Table 2 Patient, disease and treatment demographics

\begin{tabular}{lc}
\hline Parameters & $\boldsymbol{n}(\%)$ \\
\hline Median age, range & $65.6,49-82$ \\
Gender & \\
Male/Female & $49(79) / / 3(21)$ \\
Histology & \\
$\quad$ Epithelioid & $36(58)$ \\
Biphasic & $17(27)$ \\
Sarcomatoid & $9(15)$ \\
Stage & \\
I/2/3/4 & \\
WHO PS & \\
O/I/2 & $8(6) / 16(26) / 32(52) / 10(16)$ \\
Chemotherapy regimen & \\
Pemetrexed/Carboplatin & $458) / 18(29)$ \\
Pemetrexed/Cisplatin & $12(27)$ \\
Median chemotherapy cycles (range) & $4(2-6)$ \\
\hline
\end{tabular}

dialysis. A report using pemetrexed and gemcitabine in the NCIMSTO $211 \mathrm{H}$ cell line showed a two-fold higher pemetrexed $\mathrm{GI}_{50}$ value of $67 \mathrm{~nm}$ (Nagai et al, 2008), compared with the value reported here, and strong synergism was observed in these cells when pemetrexed preceded dosing with gemcitabine. Other studies found that the sensitivity of mesothelioma cell lines after $8 \mathrm{~h}$ exposure to $30 \mu \mathrm{m}$ pemetrexed was in the order $\mathrm{H} 2052>\mathrm{H} 28>\mathrm{MSTO}-211 \mathrm{H}$, and that caffeine enhanced pemetrexed activity in the mesothelioma cell lines tested (Min et al, 2008). Similar differences in pemetrexed sensitivity have also been 

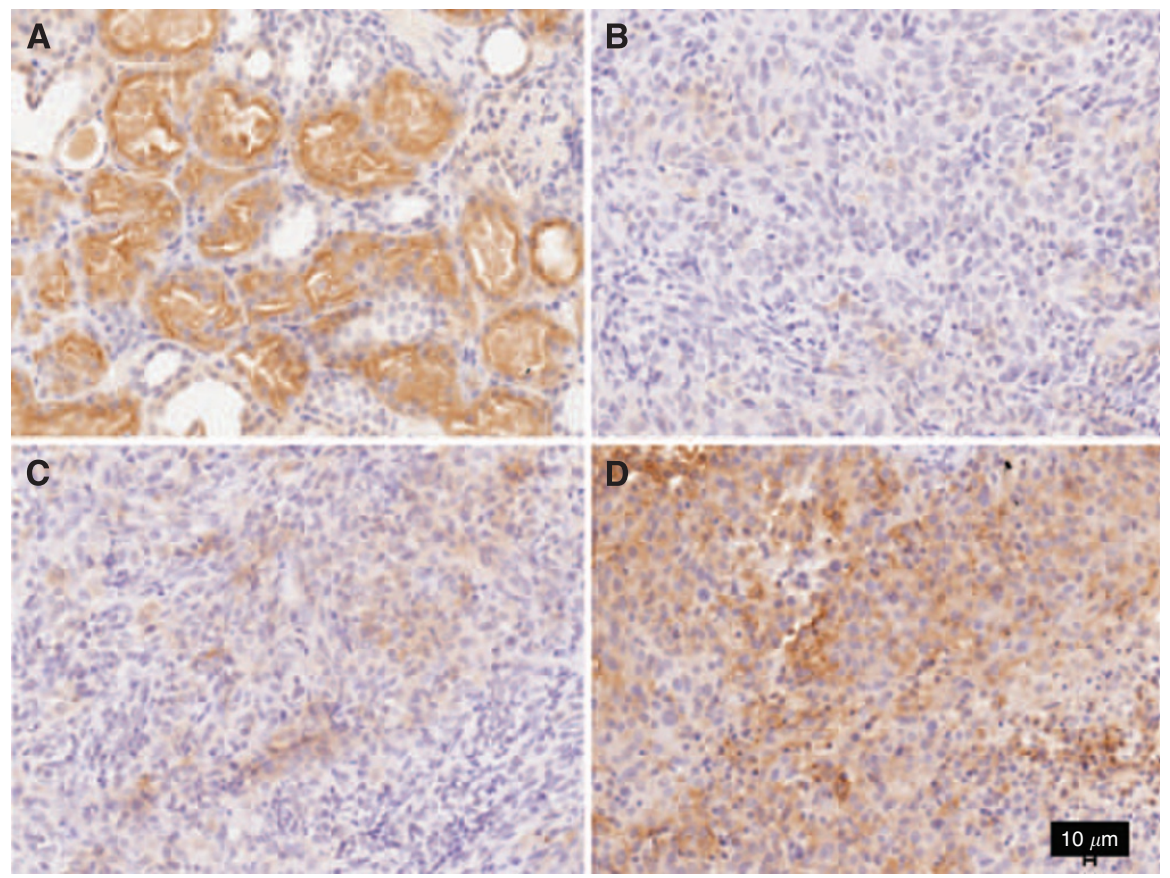

Figure 4 Folate receptor alpha $(F R \alpha)$ immunohistochemistry staining of samples of $(\mathbf{A})$ renal tissue used as positive control; (B-D) mesothelioma samples showing weak $(\mathbf{B})$, moderate $(\mathbf{C})$ and strong $(\mathbf{D})$ staining.
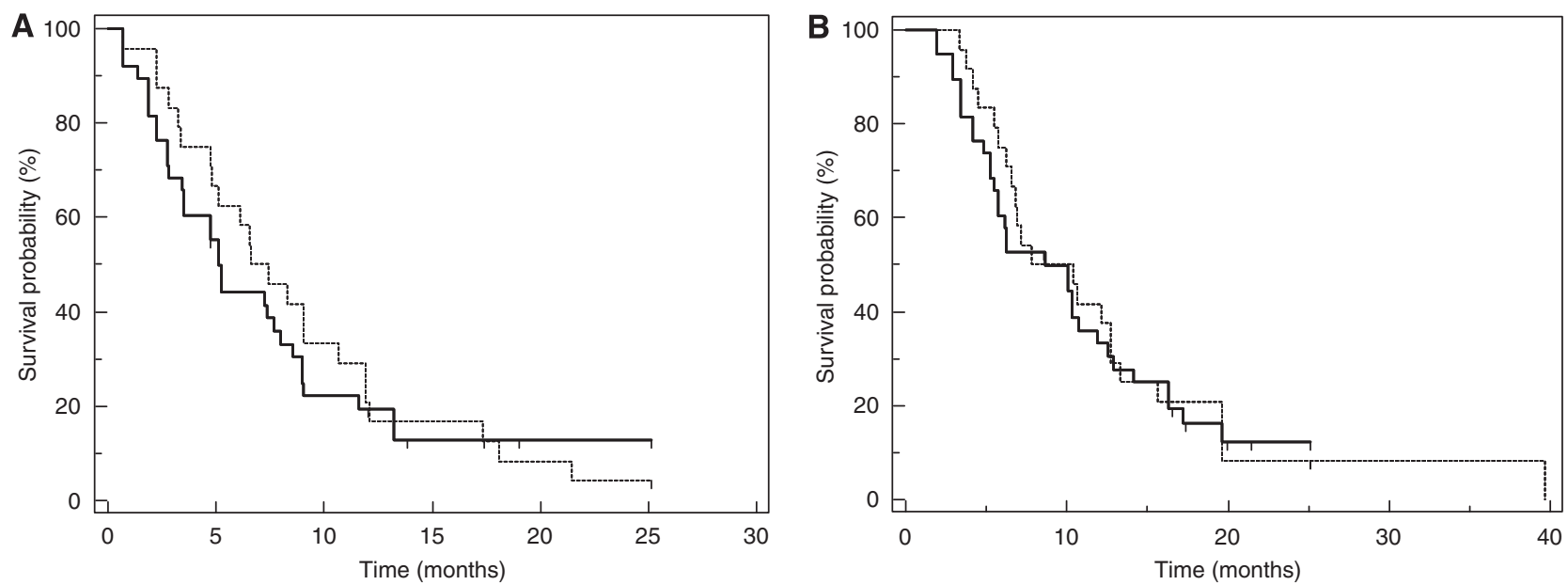

Figure 5 (A) Kaplan-Meier time-to-treatment failure (TTF) curves. (B) Kaplan-Meier overall survival (OS) curves. Solid line indicates samples with negative folate receptor alpha $(F R \alpha)$ expression $(n=38)$, dashed line indicates positive FR $\alpha$ expression $(n=24)$.

reported (Chattopadhyay et al, 2006) between $\mathrm{H} 28$ and $\mathrm{H} 2052$ cells $\left(\mathrm{GI}_{50}\right.$ values 90 and $40 \mathrm{~nm}$, respectively). It has been reported that the effect of pemetrexed is enhanced in cell lines when there is a low or physiological concentration of folate in the medium (Theti and Jackman, 2004) and that higher extra-cellular folate levels correlate inversely with pemetrexed activity in vitro in mesothelioma and other solid tumour cell lines (Chattopadhyay et al, 2007). In our studies, it was found that when using normal or lowfolate medium (results using low-folate medium are not shown) and dialysed or normal serum, the main difference in the effect of pemetrexed was seen between the dialysed serum and normal serum as reported here; hence, low-folate medium was not routinely used.

The RFC, rather than PCFT, shows the most variation in cell lines. There was no correlation between RFC or PCFT with the $\mathrm{GI}_{50}$ for pemetrexed. However, a higher RFC was seen in less sensitive cells, apart from the sensitive MSTO cells.

The ratio of epithelioid to sarcomatoid cell lines used in this study reflects the general occurrence of these different tumour types, the majority being epithelioid, $10-15 \%$ sarcomatoid and $20-35 \%$ biphasic. All cell lines used retained their typical epithelioid or sarcomatoid morphology, using FBS in the medium. Cells are generally grown in medium containing bovine serum, but no changes in morphology were seen, unlike the report of mesothelioma cell lines of different morphology (Klominek et al, 1989) established from the pleural fluid of one patient.

Folate receptor alpha was unable to be detected in western blots in any mesothelioma cell line, and was also only barely detectable by real-time PCR. It is therefore evident that the difference in sensitivity to pemetrexed in cell lines is not due 
to the presence of $F R \alpha$ and the uptake of pemetrexed into the cells through $\mathrm{FR} \alpha$.

A review on FR $\alpha$ (Kelemen, 2006) suggests that further research into the presence of FR $\alpha$ in tumours is necessary, as there is a lack of clinical studies using tumour samples, particularly in the context of pemetrexed trials. Until recently, there has been no antibody available to detect $\mathrm{FR} \alpha$ by immunohistochemistry in paraffin-embedded tumour samples, although the antibodies Mov18 and Mov19 could be used on frozen sections (Bueno et al, 2001). Another study of $\mathrm{FR} \alpha$ in samples of mesothelioma (Khokhar et al, 2002) showed no difference in $\mathrm{FR} \alpha$ gene expression (by RT-RNA) in mesothelioma of differing histological type. Following the development of an FR $\alpha$ antibody for use on paraffinembedded tissues (Smith et al, 2007), samples of mesothelioma have been used in this study for FR $\alpha$ immunohistochemistry and the results have been compared with response to treatment with pemetrexed. The protein was only detected in 39\% of tumours, which is lower than in the previous study, and staining was both membranous and cytoplasmic. Focal staining was generally observed in small regions of tumours, involving only a small percentage of tumour cells and only in two cases was the staining intense. There was no significant difference in FR $\alpha$ staining between the three histological subtypes of mesothelioma, and no difference was observed in the overall survival or time to treatment failure for patients with positive $\mathrm{FR} \alpha$ tumours compared with those with negative FR $\alpha$ tumours. FR $\alpha$ is therefore unlikely to have a major role in the uptake of pemetrexed in mesothelioma and what little expression there is does not seem to be a predictive marker for treatment response. The low levels of FR $\alpha$ expression in malignant pleural mesothelioma samples and the lack of relationship to pemetrexed treatment in this series are consistent with the cell culture observations.

\section{REFERENCES}

Bueno R, Appasani K, Mercer H, Lester S, Sugarbaker D (2001) The alpha folate receptor is highly activated in malignant pleural mesothelioma. J Thorac Cardiovasc Surg 121: 225-233

Cakir C, Gulluoglu MG, Yilmazbayhan D (2006) Cell proliferation rate and telomerase activity in the differential diagnosis between benign and malignant mesothelial proliferations. Pathology 38: 10-15

Chattopadhyay S, Tamari R, Min SH, Zhao R, Tsai E, Goldman ID (2007) Commentary: a case for minimizing folate supplementation in clinical regimens with pemetrexed based on the marked sensitivity of the drug to folate availability. Oncologist 12: $808-815$

Chattopadhyay S, Wang Y, Zhao R, Goldman ID (2004) Lack of impact of the loss of constitutive folate receptor alpha expression, achieved by RNA interference, on the activity of the new generation antifolate pemetrexed in HeLa cells. Clin Cancer Res 10: 7986-7993

Chattopadhyay S, Zhao R, Tsai E, Schramm VL, Goldman ID (2006) The effect of a novel transition state inhibitor of methylthioadenosine phosphorylase on pemetrexed activity. Mol Cancer Ther 5: 2549-2555

Hanauske AR, Chen V, Paoletti P, Niyikiza C (2001) Pemetrexed disodium: a novel antifolate clinically active against multiple solid tumors. Oncologist 6: $363-373$

Herndon JE, Green MR, Chahinian AP, Corson JM, Suzuki Y, Vogelzang NJ (1998) Factors predictive of survival among 337 patients with mesothelioma treated between 1984 and 1994 by the Cancer and Leukemia Group B. Chest 113: 723-731

Hodgson JT, McElvenny DM, Darnton AJ, Price MJ, Peto J (2005) The expected burden of mesothelioma mortality in Great Britain from 2002 to 2050. Br J Cancer 92: 587-593

Hughes A, Calvert P, Azzabi A, Plummer R, Johnson R, Rusthoven J, Griffin M, Fishwick K, Boddy AV, Verrill M, Calvert H (2002) Phase I clinical and pharmacokinetic study of pemetrexed and carboplatin in patients with malignant pleural mesothelioma. J Clin Oncol 20: 3533-3544 Kamen BA, Smith AK (2004) A review of folate receptor alpha cycling and 5-methyltetrahydrofolate accumulation with an emphasis on cell models in vitro. Adv Drug Deliv Rev 56: 1085-1097
The large differences in response to pemetrexed warrant further investigation. A recent report now provides evidence that the secondary target for the effect of pemetrexed is aminoimidazolecarboxamide ribonucleotide formyl-transferase (AICART), involved in de novo purine synthesis, rather than GARFT, (Racanelli et al, 2009), and this may explain the unusual activity of pemetrexed in lung cancers.

In conclusion, the use of a varied panel of eight mesothelioma cell lines and the investigation of a large number of tumour samples from patients with mesothelioma treated with pemetrexed in this study demonstrate that there is no relationship between response to pemetrexed and FR $\alpha$ expression in mesothelioma, or to the expression of RFC and PCFT in the cell lines. Other reasons for differences in sensitivity to pemetrexed remain to be established, but this study shows that there is no simple relationship between the sensitivity of cell lines to pemetrexed and the expression of any of the folate transporters; other potential molecular markers for pemetrexed response in mesothelioma are currently under investigation.

\section{ACKNOWLEDGEMENTS}

This work was supported by grants from Cancer Research UK (JEN), Experimental Cancer Medicine (KOT), British Lung Foundation (ARAR) and a BioNet Studentship (AEQ). We would like to thank Sebastian Lambert for technical assistance, Dr Jane Margetts for the IGROV1 cells and Dr Sally Coulthard for the Jurkat cells. We would also like to acknowledge the assistance received for the part development of this trial in the 8th Annual Workshop for 'Methods in Clinical Cancer Research' sponsored by ECCO, AACR and ASCO.
Kelemen LE (2006) The role of folate receptor alpha in cancer development, progression and treatment: cause, consequence or innocent bystander? Int J Cancer 119: $243-250$

Khokhar NZ, Lam AFY, Rusch VW, Sirotnak FM (2002) Despite some expression of folate receptor alpha in human mesothelioma cells, internalization of methotrexate is predominantly carrier mediated. J Thorac Cardiovasc Surg 123: $862-868$

Klominek J, Robert KH, Hjerpe A, Wickstrom B, Gahrton G (1989) Serumdependent growth patterns of two, newly established human mesothelioma cell lines. Cancer Res 49: 6118-6122

Mantovani LT, Miotti S, Menard S, Canevari S, Raspagliesi F, Bottini C, Bottero F, Colnaghi MI (1994) Folate binding protein distribution in normal tissues and biological fluids from ovarian carcinoma patients as detected by the monoclonal antibodies MOv18 and MOv19. Eur J Cancer 30A: $363-369$

Min SH, Goldman ID, Zhao R (2008) Caffeine markedly sensitizes human mesothelioma cell lines to pemetrexed. Cancer Chemother Pharmacol 61: $819-827$

Nagai S, Takenaka K, Sonobe M, Wada H, Tanaka F (2008) Scheduledependent synergistic effect of pemetrexed combined with gemcitabine against malignant pleural mesothelioma and non-small cell lung cancer cell lines. Chemotherapy 54: 166-175

Nutt JE, Lazarowicz HP, Mellon JK, Lunec J (2004) Gefitinib ('Iressa', ZD1839) inhibits the growth response of bladder tumour cell lines to epidermal growth factor and induces TIMP2. Br J Cancer 90: 1679-1685

Racanelli AC, Rothbart SB, Heyer CL, Moran RG (2009) Therapeutics by cytotoxic metabolite accumulation: pemetrexed causes ZMP accumulation, AMPK activation, and mammalian target of rapamycin inhibition. Cancer Res 69: $5467-5474$

Shih C, Chen VJ, Gossett LS, Gates SB, MacKellar WC, Habeck LL, Shackelford KA, Mendelsohn LG, Soose DJ, Patel VF, Andis SL, Bewley JR, Rayl EA, Moroson BA, Beardsley GP, Kohler W, Ratnam M, Schultz RM (1997) LY231514, a pyrrolo[2,3-d]pyrimidine-based antifolate that inhibits multiple folate-requiring enzymes. Cancer Res 57: 1116-1123 
Skehan P, Storeng R, Scudiero D, Monks A, McMahon J, Vistica D, Warren JT, Bokesch H, Kenney S, Boyd MR (1990) New colorimetric cytotoxicity assay for anticancer-drug screening. J Natl Cancer Inst 82: 1107-1112

Smith AE, Pinkney M, Piggott NH, Calvert H, Milton ID, Lunec J (2007) A novel monoclonal antibody for detection of folate receptor alpha in paraffin-embedded tissues. Hybridoma 26: 281-288

Theti DS, Jackman AL (2004) The role of alpha-folate receptor-mediated transport in the antitumor activity of antifolate drugs. Clin Cancer Res 10: $1080-1089$

Toffoli G, Cernigoi C, Russo A, Gallo A, Bagnoli M, Boiocchi M (1997) Overexpression of folate binding protein in ovarian cancers. Int J Cancer 74: $193-198$

Towbin H, Staehelin T, Gordon J (1979) Electrophoretic transfer of proteins from polyacrylamide gels to nitrocellulose sheets: procedure and some applications. Proc Natl Acad Sci USA 76: $4350-4354$

Vogelzang NJ, Rusthoven JJ, Symanowski J, Denham C, Kaukel E, Ruffie P, Gatzemeier U, Boyer M, Emri S, Manegold C, Niyikiza C, Paoletti P
(2003) Phase III study of pemetrexed in combination with cisplatin versus cisplatin alone in patients with malignant pleural mesothelioma. J Clin Oncol 21: 2636-2644

Wang Y, Zhao R, Chattopadhyay S, Goldman ID (2003) A novel folate transport activity in human mesothelioma cell lines with high affinity and specificity for the new-generation antifolate pemetrexed. Cancer Res 63: $7004-7004$

Weitman SD, Lark RH, Coney LR, Fort DW, Frasca V, Zurawski Jr VR, Kamen BA (1992) Distribution of the folate receptor GP38 in normal and malignant cell lines and tissues. Cancer Res 52: 3396-3401

Whetstine JR, Flatley RM, Matherly LH (2002) The human reduced folate carrier gene is ubiquitously and differentially expressed in normal human tissues: identification of seven non-coding exons and characterization of a novel promoter. Biochem J 367: 629-640

Zhao R, Qiu A, Tsai E, Jansen M, Akabas MH, Goldman ID (2008) The proton-coupled folate transporter: impact on pemetrexed transport and on antifolates activities compared with the reduced folate carrier. Mol Pharmacol 74: $854-862$ 